\title{
Serum osteopontin and CD44 levels in lymphoreticular malignancies in children
}

\author{
Elli $\mathrm{M}^{1}$, Dagdemir A ${ }^{1}$, Bozkurt $\mathrm{C}^{2}$, Pinarli FG ${ }^{1}$, Duzgun ${ }^{1}$, Ozmen $\mathrm{ZC}^{1}$, Ertem $\mathrm{U}^{2}$, Acar S ${ }^{1}$ \\ Ondokuz Mayis University, Medical Faculty, Department of Pediatric Oncology, Samsun, Turkey. \\ ellimurat@yahoo.com
}

\begin{abstract}
Objective: Osteopontin (OPN) is an adhesive glycoprotein that interacts with a variety of cell surface receptors, including several integrins and CD44. OPN is expressed and secreted by numerous human malignancies. CD44 play an important role in tumor growth and metastasis. We aimed to evaluate serum levels of osteopontin and CD44 in patients with lymphorethicular malignancies in childhood.

Methods: We studied serum levels of CD44 and OPN levels of 54 patients (26, 18 and 10 patients with nonHodgkin's lymphoma (NHL), Hodgkin's lymphoma (HL) and acute lymphoblastic leukemia (ALL), respectively) at the diagnosis.

Results: The mean levels of OPN were significantly higher in patients $(5.42 \pm 8.24 \mathrm{ng} / \mathrm{ml})$ than in controls $(3.89$ $\pm 1.96 \mathrm{ng} / \mathrm{ml})$. The mean levels of CD44 levels were also significantly higher in patients $(3.82 \pm 2.31 \mathrm{ng} / \mathrm{ml})$ than in controls $(1.96 \pm 0.62 \mathrm{ng} / \mathrm{ml})$, and significantly higher in the advanced stages than in early stages. The mean levels of the CD44 in NHL, HL and ALL were $3.49 \pm 2.00,3.56 \pm 1.74$, and $5.15 \pm 3.50$ respectively. Serum OPN and CD44 levels were found to be increased in parallel $(p=0.003)$. A more advanced disease and/or poor prognostic factors were seen in 9 patients who had both serum CD44 and OPN levels higher than 2SD of the control. Conclusion: Elevated levels of both CD44 and OPN at the diagnosis may predict an unfavorable outcome in childhood leukemias and lymphomas (Tab. 2, Fig. 3, Ref. 44). Full Text in PDF www.elis.sk.

Key words: osteopontin, CD44, lymphoma, leukemia, children.
\end{abstract}

Osteopontin (OPN) is an arginine-glycine-aspartate containing adhesive glycoprotein first identified in bone and subsequently detected in many other tissues, including dentin, cartilage, kidney, and vascular tissues. OPN is involved in diverse biologic processes, including inflammation, leukocyte recruitment, wound healing, and cell survival $(1-4)$. In addition to these pathologic processes, OPN might have a protective role in interactions between epithelial surfaces and the external environment (5). OPN is expressed and secreted by numerous human cancers and functions in cell adhesion, chemotaxis, macrophage-directed interleukin 10 (IL-10) suppression, stress-dependent angiogenesis, prevention of apoptosis, anchorage-independent growth of tumor cells by regulating cell-matrix interactions and cellular signaling through binding with integrin and CD44 receptors (6). The CD44 glycoproteins are ubiquitously expressed cell-surface adhesion molecules that mediate cell-matrix and cell-cell interactions (7). CD44 may play an important role in tumor growth and metastasis. Many of the primary carcinoma specimens examined expressed high levels of CD44 (8). Serum CD44 concentration is found to be correlated

${ }^{1}$ Ondokuz Mayis University, Medical Faculty, Department of Pediatric Oncology, Samsun, Turkey, and ${ }^{2}$ Dr Sami Ulus Children Hospital, Department of Pediatric Oncology, Ankara, Turkey

Address for correspondence: M. Elli, MD, Ondokuz Mayis University, Medical Faculty, Department of Pediatric Oncology, Samsun, Turkey.

Acknowledgments: This study was supported by Ondokuz Mayis University Research Fund. with tumor metastasis and tumor burden, and surgical resection of tumors resulted in decreases in serum CD44 levels (9). In this study, we aimed to measure serum levels of osteopontin and CD44 in patients with lymphorethicular malignancies in childhood and to determine the relation of osteopontin levels with disease stage.

\section{Materials and methods}

\section{Patients}

We studied the serum levels of CD44 and OPN in 54 patients with non-Hodgkin's lymphoma (NHL, 26 patients), Hodgkin's lymphoma (HL, 18 patients) and acute lymphoblastic leukemia (ALL, 10 patients). The blood samples were obtained at diagnosis in division of the Pediatric Hematology and Oncology at Ondokuz Mayis University and Dr. Sami Ulus Children's Hospital, then centrifuged and the supernatant was stored at $-80^{\circ} \mathrm{C}$ until the analysis. Stage III and IV NHL and HL and all leukemia were defined as advanced disease. Age and sex-matched 20 healthy children were enrolled to the study as the control group. Informed consent was obtained for all children from their parents.

\section{Detection of serum $C D 44$}

Serum soluble CD44 (sCD44) was measured with an enzymelinked immunosorbent assay (CD44 ELISA; Bender Med Systems, Vienna, Austria). The Human sCD44std ELISA BMS209/2 ${ }^{\circledR}$ is the enzyme-linked immunosorbent assay for the quantitative detection of human sCD44std. The anti-human sCD44std coating antibody 
is adsorbed onto micro wells. Human sCD44std present in the sample or standard binds to antibodies adsorbed to the micro wells. The HRP-conjugated anti-human sCD44std antibody is added and binds to human SCD44std captured by the first antibody. Following incubation, unbound HRP conjugated anti-human sCD44std is removed during a wash step, and substrate solution reactive with HRP is added to the wells. A colored product is formed in proportion to the amount of human SCD44std present in the sample or standard. The reaction is terminated by addition of acid and absorbance is measured at $450 \mathrm{~nm}$. A standard curve is prepared from 6 human sCD44std standard dilutions and human sCD44std concentration is determined.

\section{Detection of human osteopontin in serum}

Assay Designs' human OPN TiterZyme ${ }^{\circledR}$ Enzyme Immunometric Assay (EIA) kit is a complete kit for the quantitative determination of OPN in human biological fluids. The kit uses a monoclonal antibody to human OPN immobilized on a microtiter plate to bind the human OPN in the standards or sample. A recombinant human OPN Standard is provided in the kit. After a short incubation, the excess sample or Standard is washed out and a biotinylated monoclonal antibody to human OPN is added. This antibody binds to the human OPN captured on the plate. After a short incubation, the excess antibody is washed out and Streptavidin conjugated to Alkaline Phosphatase is added, which binds to the biotinylated monoclonal human OPN antibody. An excess conjugate is washed out and substrate is added. After a short incubation, the enzyme reaction is stopped and the color generated is read at $405 \mathrm{~nm}$. The measured optical density is directly proportional to the concentration of human OPN in either standards or samples.

\section{Statistical analyses}

The data were analyzed on the SPSS 9.05 packed program for windows. The mean levels of osteopontin and sCD44 levels of the groups were compared to the Mann-Whitney U test. The Pearson correlation test was used for searching a correlation between sCD44, osteopontin levels and the other parameters including serum LDH levels, age, subtypes of the disease (leukemia, nonHodgkin's and Hodgkin's lymphoma), white blood cell count and primary site of the disease.

\section{Results}

The mean levels of sCD44 levels were $3.82 \pm 2.31$ and 1.96 $\pm 0.62 \mathrm{ng} / \mathrm{ml}$ in patients and controls, respectively, and the difference between them was significant $(p=0.01)$ (Fig. 1, Tab. 1). On the other hand, the mean levels of OPN were $5.42 \pm 8.24$ and $3.89 \pm 1.96 \mathrm{ng} / \mathrm{ml}$ in patients and controls, respectively, and the difference between them was not significant ( $p=0.214$ ) (Fig. 2). The mean levels of the sCD44 in ALL, NHL and HL were $5.15 \pm$ $3.50,3.49 \pm 2.00$ and $3.56 \pm 1.74$, respectively. The mean levels of OPN in ALL, NHL and HL were 7.24 $\pm 7.13,5.95 \pm 8.52$ and $3.63 \pm 1.86$, respectively (Tab. 1). When we looked at the levels of the subgroups of the disease, sCD44 levels in NHL, HL and ALL levels were significantly higher than the levels of control group

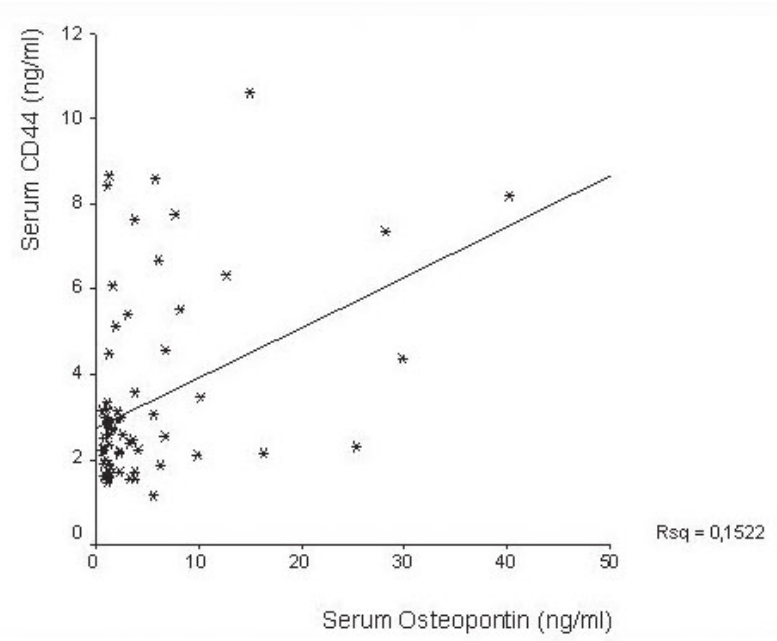

Fig. 1. Box plots of serum CD44 levels of the groups. CD44 levels in NHL, HL and ALL were significantly higher than in the control group ( $p$ values were $0.001,0.001$ and 0.022 , respectively).

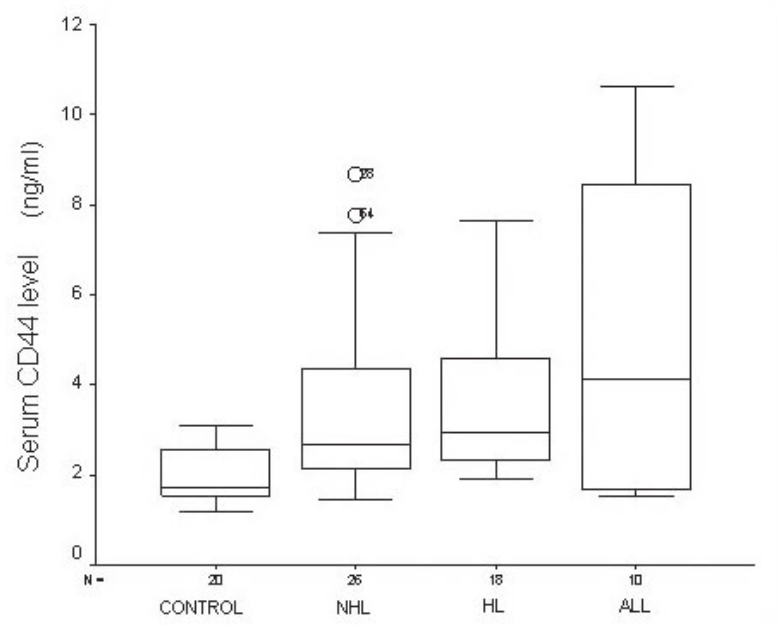

Fig. 2. Box plots of serum osteopontin levels of the groups. OPN levels in the same groups were not significantly higher than in the control group ( $p$ values were $0.297,0.105$ and 0.286 , respectively).

( $p$ values were $0.001,0.001$ and 0.022 , respectively). On the other hand, OPN levels of the same groups were not significantly higher than the levels of control group ( $\mathrm{p}$ values were 0.297, 0.105 and 0.286 , respectively) (Tab.1).

Serum CD44 levels were significantly higher in advanced stage of the disease than in early stages of lymphomas $(4.04 \pm 2.08$ and $2.43 \pm 0.52)(p=0.05)$. Serum OPN levels were also higher in advanced stage of the disease than in early stages (6.01 \pm 8.12 and $3.05 \pm 4.34)$ but not statistically significant $(\mathrm{p}=0.061)$ (Tab. 1). The levels of OPN correlated with $\mathrm{sCD} 44$ ( $\mathrm{p}=0.003)$ (Fig. 3). The levels of sCD44 and OPN correlated with serum LDH levels but not with other parameters including age, subtypes of the disease (leukemia, non-Hodgkin's and Hodgkin's lymphoma), white blood cell count and primary site of the disease.

Both sCD44 and OPN were detected above 2SD of the control group in 9 patients (ALL: 2, NHL: 5 and HL: 2 patients). 
Tab. 1. Serum levels of CD44 and osteopontin of the patients and control groups.

\begin{tabular}{llllc}
\hline & Control (Mean \pm SD) & \multicolumn{2}{l}{ Patients $($ Mean \pm SD) } & p \\
\hline \multirow{4}{*}{ CD44 } & & Total & $3.82 \pm 2.31$ & 0.010 \\
& \multirow{3}{*}{$1.96 \pm 0.62$} & NHL & $3.49 \pm 2.00$ & 0,001 \\
& & HL & $3.56 \pm 1.74$ & 0,001 \\
& & ALL & $5.15 \pm 3.50$ & 0,022 \\
\hline \multirow{3}{*}{ Osteopontin } & \multirow{3}{*}{$3.89 \pm 1.96$} & Total & $5.42 \pm 8.24$ & 0.214 \\
& & NHL & $5.95 \pm 8.52$ & 0.297 \\
& & HL & $3.63 \pm 1.86$ & 0.105 \\
& & ALL & $7.24 \pm 7.13$ & 0.286 \\
\hline
\end{tabular}

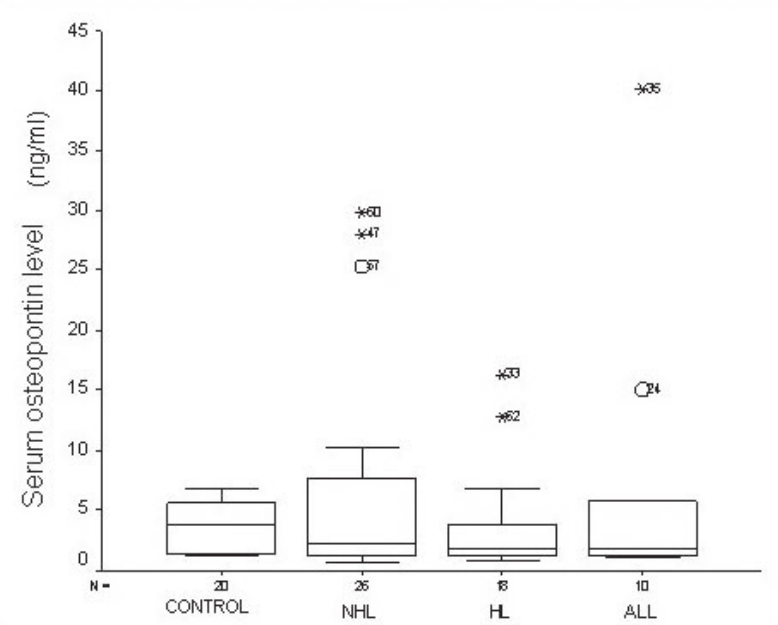

Fig. 3. Comparison of serum CD44 and osteopontin levels. The levels of OPN correlated with CD44 $(\mathrm{p}=\mathbf{0 . 0 0 3})$.

One of the ALL patients relapsed in CNS and bone marrow and subsequently died. The other also had CNS disease but achieved a complete remission. Two cases with NHL presented with bone marrow involvement. Furthermore, two other cases of NHL presented with bulky masses: one of them had vena cava superior syndrome and the other one with large abdominal masses had an intestinal perforation (Tab. 2).

\section{Discussion}

Osteopontin is an acidic extra cellular matrix cell adhesion protein that is relatively abundant not only in bone matrix, plasma, urine, and milk, but is also found in malignant tissue. OPN is a multifunctional phosphoprotein secreted by many cell types including osteoclasts, epidermal cells, activated immune cells such as $\mathrm{T}$ cells, natural killer cells, macrophages, Kupffer cells, and tumor cells. Phosphorylation, glycosylation and calcium modifications allow intact and fragmented OPN to direct a variety of diverse responses including tissue remodeling, inflammation and cell survival $(2-4,10,11)$.

Multiple and complex mechanisms are involved in the role of OPN in cancer (12-17). Osteopontin interacts with a variety of cell surface receptors, including several integrins and CD44. Binding of osteopontin to these cell surface receptors stimulates cell adhesion, migration, and specific signaling functions $(6,9)$. CD44 is a glycoprotein present in a wide variety of non-neoplastic and neoplastic cells $(9,18,19)$. CD44 isoforms' major physiological role is to maintain organ and tissue structure via cell-cell and cell-matrix adhesion, but certain variant isoforms can also mediate lymphocyte activation and homing, and the presentation of chemical factors and hormones (29). CD44 may play an important role in tumor growth and metastasis. Many of the primary carcinoma specimens examined expressed high levels of CD44. CD44 is highly expressed in many tumors and is correlated with the tumor biological behavior including tumorigenesis, growth, metastasis and prognosis (20-22). Overexpression of OPN has been found in a variety of cancers, including breast (23), lung (24), colorectal (25), stomach (26), ovarian (27), liver (28) and prostate cancers (29). Moreover, OPN is present in elevated levels in the blood and plasma of some patients with metastatic cancers. Recently, some authors suggested that OPN levels in the blood or tumors of cancer patients might provide useful clinical information for the patient prognosis $(27,30,31)$ and stage of disease (32). In our study, the mean levels of OPN were significantly higher in patients than in controls and also higher in advanced stage of the disease than in early stages, but not statistically significant. This result may be due to the small number of patients

Over expression of CD44 is associated with an aggressive behavior, dissemination, advanced stages and poor prognosis of human non-Hodgkin's lymphomas, Hodgkin's and nodal diffuse lymphomas $(19,33-36)$. Serum CD44 levels were significantly declined in HL and NHL patients, who were in a complete remission. Therefore, it may be useful as a marker of treatment response (19). High serum CD44 levels were also associated with a high tumor tissue expression of CD44 in patients with $\mathrm{HD}$ and BL. In

Tab. 2. Characteristics of patients with advanced disease whose CD44 and OPN were detected above 2SD.

\begin{tabular}{|c|c|c|c|c|c|c|c|c|c|c|c|}
\hline Age & Disease & Cytology & Stage & $\begin{array}{l}\text { Bone marrow } \\
\text { involvement }\end{array}$ & $\begin{array}{c}\text { CNS } \\
\text { involvement }\end{array}$ & WBC & $\mathrm{LDH}$ & $\begin{array}{c}\text { Current } \\
\text { status }\end{array}$ & Relaps & CD44 & OPN \\
\hline 15 & ALL & pre-B ALL & & + & + & 15500 & 1597 & Ex (died of disease) & 1 & 10.618 & 15.00 \\
\hline 3 & ALL & pre-B ALL & & + & + & 13700 & 377 & alive & 0 & 8.170 & 40.06 \\
\hline 15 & ALL & pre-B ALL & & + & - & 39200 & 4579 & alive & 0 & 8.583 & 5.76 \\
\hline 6 & NHL & pre-B ALL & & + & - & 10300 & 2980 & alive & 0 & 7.344 & 28.05 \\
\hline 10 & HL & & IV & & & & & alive & 0 & 6.663 & 6.10 \\
\hline 11 & NHL & & III & & & & & alive & 0 & 4.355 & 29.79 \\
\hline 10 & Hodgkin & NS & IV & - & - & 3600 & 181 & alive & 0 & 6.306 & 12.74 \\
\hline 7 & NHL & Burkitt lymphoma & III & - & - & 11500 & 1324 & alive & 0 & 3.451 & 10.27 \\
\hline 3 & NHL & T Cell LBL & III & - & - & 13100 & 1700 & alive & 1 & 5.517 & 8.26 \\
\hline
\end{tabular}


addition, patients with higher levels of serum $\mathrm{SCD} 44$ had a poorer outcome and survival than those with lower SCD44 levels in HL and NHL groups $(19,36)$. CD44 overexpression has been showed to be associated with poor prognosis in a number of hematological malignancies, such as acute myeloid leukemia, acute lymphoblastic leukemia, chronic lymphoblastic leukemia, lymphoma, and multiple myeloma (37 - 39). Tacyildiz et al (36) detected that serum CD44 levels were significantly higher in pediatric patients with HL, NHL and Burkitt's lymphoma (BL) compared to the control group. In our study, the mean levels of sCD44 levels in patients were significantly higher than in the control group. Also, the serum CD44 levels were significantly higher in advanced stages of the disease than in early stages. The levels of CD44 and OPN correlated with serum LDH levels.

Yang et al (40) found that OPN combined with CD44 might be of value as an unfavorable prognostic factor for patients with hepatocellular carcinoma. It has been reported that OPN expression in human cancer cells increases CD44 surface expression (41-43). Furthermore, Marroquin et al (44) reported that OPN increases plasma membrane CD44 expression and cell adhesion by binding to its $\alpha_{v} \beta_{3}$-integrin receptor in RAW 264.7 murine leukemia cells and suggested that OPN may promote tumor metastatic behavior by CD44 expression. We found that OPN and CD44 levels were elevated in childhood lymphoreticular malignancies. Also, both CD44 and OPN levels were detected above 2SD in 9 patients with advanced disease in our study (Tab. 2).

As a result, elevated levels of both CD44 and OPN at the diagnosis may give more information on prognosis in childhood leukemias and lymphomas. Additional studies including larger series of patients and monitoring of these levels in the progress of the disease are needed to confirm whether these markers give more information about unfavorable outcome of these cancers.

\section{References}

1. Senger DR, Wirth DF, Hynes RO. Transformed mammalian cells secrete specific proteins and phosphoproteins. Cell 1979; 16: 885 - 893

2. Prince CW, Oosawa T, Butler WT et al. Isolation, characterization, and biosynthesis of a phosphorylated glycoprotein from rat bone. J Biol Chem 1987; 262: 2900 - 2907.

3. Higashibata Y, Sakuma T, Kawahata $\mathbf{H}$ et al. Identification of promoter regions involved in cell- and developmental stage-specific osteopontin expression in bone, kidney, placenta and mammary gland: an analysis of transgenic mice. J Bone Miner Res 2004; 19: 78 - 88.

4. Takahashi F, Takahashi K, Shimizu K et al. Osteopontin is strongly expressed by alveolar macrophages in the lungs of acute respiratory distress syndrome. Lung 2004; 182: 173 - 185.

5. Rodrigues LR, Teixerira JA, Schmitt F et al. The role of osteopontin in tumor progression and metastasis in breast cancer. Cancer Epidemiol Biomarkers Prev 2007; 16: 1 - 11.

6. Wai PY, Kuo PC. The role of osteopontin in tumor metastasis. J Surg Res 2004; 121: 228 - 241 .

7. Goodison S, Urquidi V, Tarin D. CD44 cell adhesion molecules. Mol Pathol 1999; 52: 189 - 196.
8. Stamenkovic I, Aminot M, Pesando JM, Seed B. A lymphocyte molecule implicated in lymph node homing is a member of the cartilage link protein family. Cell 1989; 56: $1057-1062$.

9. Guo YJ, Liu G, Wang X et al. Potential use of soluble CD44 in serum as indicator of tumor burden and metastasis in patients with gastric or colon cancer. Cancer Res 1994; 54: 422 - 426.

10. Furger KA, Menon RK, Tuck AB et al. The functional and clinical roles of osteopontin in cancer and metastasis. Curr Mol Med 2001; 1: $621-632$.

11. Rittling SR, Chambers AF. Role of osteopontin in tumour progression. Br J Cancer 2004; 90: 1877 - 1881.

12. Crawford HC, Matrisian LM, Liaw L. Distinct roles of osteopontin in host defense activity and tumor survival during squamous cell carcinoma progression in vivo. Cancer Res 1998; 58: 5206 - 5215.

13. Gardner HA, Berse B, Senger DR. Specific reduction in osteopontin synthesis by antisense RNA inhibits the tumorigenicity of transformed Rat1 fibroblasts. Oncogene 1994; 9: 2321 - 2326.

14. Tuck AB, Arsenault DM, O'Malley FP et al. Osteopontin induces increased invasiveness and plasminogen activator expression of human mammary epithelial cells. Oncogene 1999; 18: 4237 - 4246.

15. Lecrone V, Li W, Devoll RE et al. Calcium signals in prostate cancer cells: specific activation by bone- matrix proteins. Cell Calcium 2000; 27: $35-42$.

16. Thalmann GN, Sikes RA, Devoll RE et al. Osteopontin: possible role in prostate cancer progression. Clin Cancer Res 1999; 5: 2271 - 2277.

17. Hirama M, Takahashi F, Takahaski K et al. Osteopontin overproduced by tumor cells acts as a potent angiogenic factor contributing to tumor growth. Cancer Lett 2003; 198: 107 - 117.

18. Iida N, Bourguignon LY. New CD44 splice variants associated with human breast cancers. J Cell Physiol 1995; 162: 127 - 133.

19. Ristamaki R, Joensuu H, Salmi M, Jalkanen S. Serum CD44 in malignant lymphoma: an association with treatment response. Blood 1994; 84: $238-243$.

20. Le QT, Chen E, Salim A et al. An evaluation of tumor oxygenation and gene expression in patients with early stage non-small cell lung cancers. Clin Cancer Res 2006; 12: 1507 - 1514.

21. Cho EY, Choi Y, Chae SW et al. Immunohistochemical study of the expression of adhesion molecules in ovarian serous neoplasms. Pathol Int 2006; 56: $62-70$.

22. Watanabe O, Kinoshita J, Shimizu T et al. Expression of a CD44 variant and VEGF-C and the implications for lymphatic metastasis and long-term prognosis of human breast cancer. J Exp Clin Cancer Res 2005; 24: $75-82$.

23. Tuck AB, O'Malley FP, Singhal $\mathbf{H}$ et al. Osteopontin and p53 expression are associated with tumor progression in a case of synchronous, bilateral, invasive mammary carcinomas. Arch Pathol Lab Med 1997; 121: $578-584$.

24. Zhang J, Takahashi K, Takahashi F et al. Differential osteopontin expression in lung cancer. Cancer Lett 2001; 171: 215 - 222.

25. Agrawal D, Chen T, Irby R et al. Osteopontin identified as lead marker of colon cancer progression, using pooled sample expression profiling. $\mathrm{J}$ Natl Cancer Inst 2002; 94: 513 - 521.

26. Ue T, Yokozaki H, Kitadai Y et al. Co-expression of osteopontin and CD44v9 in gastric cancer. Int J Cancer 1998; 79: 127 - 132. 
$534-538$

27. Kim JH, Skates SJ, Uede T et al. Osteopontin as a potential diagnostic biomarker for ovarian cancer. JAMA 2002; 287: 1671 - 1679.

28. Gotoh M, Sakamoto M, Kanetaka K et al. Overexpression of osteopontin in hepatocellular carcinoma. Pathol Int 2002; 52: $19-24$.

29. Fedarko NS, Jain A, Karadag A et al. Elevated serum bone sialoprotein and osteopontin in colon, breast, prostate, and lung cancer. Clin Cancer Res 2001; 7: 4060 - 4066.

30. Singhal H, Bautista DS, Tonkin KS et al. Elevated plasma osteopontin in metastatic breast cancer associated with increased tumor burden and decreased survival. Clin Cancer Res 1997; 3: 605-611.

31. Agrawal D, Chen T, Irby $\mathbf{R}$ et al. Osteopontin identified as lead marker of colon cancer progression, using pooled sample expression profiling. J Natl Cancer Inst 2002; 94: 513 - 521.

32. Ang C, Chambers AF, Tuck AB et al. Plasma osteopontin levels are predictive of disease stage in patients with transitional cell carcinoma of the bladder. BJU Int 2005; 96: $803-805$.

33. Koopman G, Heider KH, Horst E et al. Activated human lymphocytes and aggressive non-Hodgkin's lymphomas express a homologue of the rat metastasis-associated variant of CD44. J Exp Med 1993; 177: $897-904$.

34. Pals ST, Horst E, Ossekoppele GJ et al. Expression of lymphocyte homing receptor as a mechanism of dissemination in non-Hodgkin's lymphoma. Blood 1989; 73: $885-888$.

35. Jalkanen S, Joensuu H, Soderstrom KO, Klemi P. Lymphocyte homing and clinical behavior of non-Hodgkin's lymphoma. J Clin Invest 1991: $87: 1835-1840$.

36. Tacyildiz N, Cavdar AO, Yavuz G et al. Serum levels and differential expression of CD44 in childhood leukemia and malignant lymphoma: correlation with prognostic criteria and survival. Pediatr Int 2001; 43: $354-360$.
37. Liu J, and Jiang G. CD44 and hematologic malignancies. Cell Mol Immunol 2006; 3: $359-365$.

38. Legras S, Günthert U, Stauder R et al. A strong expression of CD44$6 \mathrm{v}$ correlates with shorter survival of patients with acute myeloid leukemia. Blood 1998; 9: 3401 - 3413.

39. Magyarosy E, Sebestyen A, Timar J. Expression of metastasis associated proteins, CD44v6 and NM23-H1, in pediatric acute lymphoblastic leukemia. Anticancer Res 2001; 21: $819-823$.

40. Yang GH, Fan J, Xu Y, Qiu SJ, Yang XR, Shi GM, Wu B, Dai Z, Liu YK, Tang ZY, Zhou J. Osteopontin combined with CD44, a novel prognostic biomarker for patients with hepatocellular carcinoma undergoing curative resection. Oncologist. 2008; 13: 1155 - 1165.

41. Samanna V, Wei H, Ego-Osuala D, Chellaiah MA: Alpha-V-dependent outside-in signaling is required for the regulation of CD44 surface expression, MMP-2 secretion, and cell migration by osteopontin in human melanoma cells. Exp Cell Res 2006; 312: 2214 - 2230.

42. Desai B, Rogers MJ, Chellaiah MA. Mechanism of osteopontin and CD44 as a metastatic principle in prostate cells. Mol Cancer 2007; 6: $18-33$.

43. Khan SA, Cook AC, Kappil M, Günthert U, Chambers AF, Tuck AB, Denhardt DT. Enhanced cell surface CD44 variant (v6, v9) expression by osteopontin in breast cancer epithelial cells facilitates tumor cell migration: Novel post-transcriptional, post-translational regulation. Clin Exp Metastasis 2005; 22: 663-673.

44. Marroquin CE, Downey L, Guo H, Kuo PC. Osteopontin increases CD44 expression and cell adhesion in RAW 264.7 murine leukemia cells. Immunol Lett 2004; 95: 109 - 112 .

Received April 16, 2011. Accepted June 26, 2012. 